\title{
Challenging the five-stage model for e-learning: a new approach
}

Pam Moule*

University of the West of England, UK

The five-stage approach to e-moderating has provided a coherent model upon which to base online learning design in higher education. However, despite its growing popularity, there are concerns that the model is becoming a dominant discourse, being adapted as a template for the design of all online teaching and learning, to the exclusion of other ideas. It is suggested that the five-stage model may not be the panacea it appears and alternative models of e-learning cannot be ignored. This paper reviews the five-stage model and contrasts it with a new conceptual model, 'the e-learning ladder', conceived as part of research with healthcare students in the higher education setting.

\section{Introduction}

The integration of e-learning into higher education pedagogy has occurred against a backdrop that includes the development of a unified e-learning strategy (Department for Education and Skills, 2005) and an increased focus on setting priorities for elearning research. Currently, the UK Joint Information Systems Committee is funding an e-Learning Programme. ${ }^{1}$ This includes an e-learning and pedagogy strand with a focus on both designing for and understanding learning, including consideration of learner participation in, and experience of, e-learning (Beetham, 2005).

One of the most popular process-based online teaching and learning models is that conceived by Salmon (2000, 2003). It is designed to demonstrate learner participation in online learning and the role of the e-moderator or online facilitator. This fivestage approach 'Model of Teaching and Learning Online' provides a model that is easily understood and employed by a number of e-moderators within higher education, although it may not be the panacea it appears.

This paper reviews Salmon's five-stage model and contrasts it with a more embracing conceptual model of e-learning, 'the e-learning ladder', developed as part of doctoral research completed within a higher education setting (Moule, 2005, 2006a).

\footnotetext{
*University of the West of England, Faculty of Health and Social Care, Glenside Campus, Blackberry Hill, Stapleton, Bristol BS16 1DD, UK. Email: pam.moule@uwe.ac.uk
} 
The ladder design was based on the interpretations of research that asked whether students of the healthcare professions could develop the essential components of a Community of Practice (Wenger, 1998), while engaged in online learning. As such it represents the learner's experiences of e-pedagogy. It reflects an interpretation of elearning that encompasses instructivist, where the learner takes a more passive role learning from provided knowledge, through to constructivist learning approaches, seen as learner focused, and endorses the building of learning on previous experience and learning (Peters, 2000).

\section{e-Moderating: the five-stage model}

Developed following research into online education and training with the Open University, Salmon's (2003) model features five stages (see Table 1) presented as a flight of steps. Each stage identifies technical and e-moderating skills required, with an interactivity bar running along the steps that indicates varying amounts of interaction expected between the participants at each stage. This is seen as greatest towards the end of stage three (information exchange), throughout stage four (knowledge construction) and into stage five (development). Participants are expected to progress through each of the five stages as part of online networking and group working. The structure is designed to support a constructivist approach to learning.

This constructivist model of e-moderating provides a framework with clear progressive stages that can support the design and facilitation of online courses. It received a number of uncritical citations in the United Kingdom when initially published (Good, 2001; Barker, 2002, Bennett $\&$ Marsh, 2002; Thorpe, 2002). Its clarity has generated wide appeal, and consequently the model has been applied in structuring online programmes (Lisewski \& Joyce, 2003; Hughes et al., 2004). It should be recognised, however, that the e-moderating model was developed from experiences of facilitating online networking and group working. Its principle purpose is to provide a model for e-moderators to support student engagement and learning online, employing constructivist pedagogic theory (Salmon, 2003). Consequently, it is limited because the variety of e-learning approaches available for use within

Table 1. An interpretation of the five-stage model (Salmon, 2003, p. 29)

\begin{tabular}{lll}
\hline Five stages of the model & Technical skills & e-Moderating activity \\
\hline $\begin{array}{l}\text { 1. Access and motivation } \\
\text { 2. Online socialisation }\end{array}$ & $\begin{array}{l}\text { Setting up system and accessing } \\
\text { Sending and receiving messages }\end{array}$ & $\begin{array}{l}\text { Welcoming and encouraging } \\
\text { Familiarising and providing } \\
\text { bridges between culture, social } \\
\text { and learning environments }\end{array}$ \\
3. Information exchange & $\begin{array}{l}\text { Searching, personalising } \\
\text { software } \\
\text { Conferencing }\end{array}$ & $\begin{array}{l}\text { Facilitating tasks and supporting } \\
\text { use of learning materials }\end{array}$ \\
$\begin{array}{l}\text { 4. Knowledge construction } \\
\text { F. Development }\end{array}$ & $\begin{array}{l}\text { Facilitating process } \\
\text { Supporting - responding }\end{array}$ \\
& & \\
\hline
\end{tabular}


computer-mediated communication is neglected and the range of learning theories available is ignored.

Not all e-learning occurs as part of a community; learning from a CD-ROM or from interactive web-based packages can be an individual and instructivist activity. The learners would be gaining objective information, such as through the basic life support CD-ROM (Moule, 2002), however, are seen as passive recipients of knowledge (Armitage \& O'Leary, 2003). While constructivist online learning communities are often adopted in higher education (Wong et al., 2003), the five-stage model has not reflected the potential available to use e-learning as part of an integrated approach that includes face-to-face delivery. Indeed, Chowcat (2005) found the model ineffective when used to train those mentoring head teachers in the United Kingdom. Chowcat suggested the model assumes an exclusive online environment will be used to support a course run to a specific timeframe of one week for each stage. The course structure proved difficult to sustain in the school year, with Chowcat concluding that the model may not readily transfer to different learning situations.

There are further concerns that the model is dominating discourse in learning technologies, being seen as a template for the design of all online teaching and learning environments regardless of the context. There is a broad concern that the reification of models of learning and teaching, while meeting organisation needs for transferable, multi-use products, will dominate and stifle professional practice development. For example, Lisewski and Joyce (2003) presented difficulties seen when using the fivestage model as a template for an e-moderating training course. The course failed to take account of individual learning styles and the rigid application of its design was difficult to challenge. This led them to highlight the dangers of reification. Objectifying the model transforms it to a product that is seen as a 'one size fits all', for use across any number of teaching and learning contexts. Paradoxically, reification of the model undermines its ethos, which seeks to support reflective practice. Through slavishly applying the model as a rigid course, any opportunities to develop flexibility and reflexivity are lost.

Further research by Jones and Peachey (2005) presents a critical review of the fivestage model. Their main criticisms are levelled at the stages of socialisation. Jones and Peachey included face-to-face contact as part of the initial stage. They were unable to determine whether an 'appropriate' level of socialisation was achieved here, as little guidance is offered that allows such measurement. Furthermore, activities in Stage two were subdued, with a reduced number of postings seen. This led Jones and Peachey (2005) to suggest that stage two may be omitted if initial socialisation in stage one has been effective. The findings also suggest those employing the model might need further guidance to enable judgements about the readiness of participants to progress through the stages of the model.

\section{e-Learning ladder: theoretical development}

The e-learning ladder was conceived as part of research exploring whether the essential characteristics of Communities of Practice (Wenger, 1998) develop in higher 
education online learning environments (see Moule, 2005, 2006a, b). Conducted in a university using a case-study approach (Yin, 1994), data were collected from healthcare students taking part in a six-week online module. From the sample of 15, five students completed online diaries, three students were interviewed and a group of seven students were involved in an online discussion board.

An increasing number of studies are applying Wenger's (1998) theory to online learning contexts as interest in constructivist approaches to e-learning develop. Conducted in America, Rogers (2000) sampled 26 teachers and administrators participating in a three-week workshop, 'Teachers of English as a Second or Other Language'. Online dialogue was analysed, suggesting the presence of Wenger's (1998) elements of mutual engagement, joint enterprise and shared repertoire. A further study of three software engineering students in the United Kingdom is presented by Chalk (2001). Based on limited analysis of team documentation and responses to a 'hidden' examination question, Chalk (2001) implied students' online experiences constituted a Community of Practice. Both case studies have a number of weaknesses and the results should be interpreted with caution. In particular, the small sample sizes and limited periods of engagement weaken the conclusions. Indeed, Hildreth (2004) presents a further case study of an online Community of Practice, highlighting some of the problems and issues involved in trying to build relationships across dispersed boundaries.

Wenger's (1998) theory has also been employed in the evaluation of a virtual learning environment, built to support an undergraduate medical course (Ellaway et al., 2004), identifying aspects of the learning environment that could be improved. Earlier research used the theory to review online working, with Somekh and Pearson (2000) analysing electronic interactions among researchers during a European project that considered children's representation of information and communication technology (ICT). Dispersed working seemed to confound the negotiation of joint enterprise, with deadlines often being missed. Different shared repertoires and histories of research methods affected mutual engagement, as participants were unable to develop shared understanding of the action research approach used. More recently, Seale (2004) applied the theory to the interpretation of a literature review that explored the enterprise of accessibility practices in e-learning. The findings highlighted the need for learning technologists to share accessibility practices and focus on the process of accessibility, rather than the product.

Finding similar results to Rogers (2000) and Chalk (2001), elements of mutual engagement, joint enterprise and shared repertoire emerged from the analysis of the textual data collected in this study. The results suggested healthcare students were able to develop a Community of Practice, although this was not uniformly seen (Moule, 2005, 2006a). It was apparent that operating within a Community of Practice online held complications arising from the e-based context of learning (Moule, 2006a). The emerging issues were related to access, trust development, the need for technical skills and support, facilitation issues, group working and the effects of longevity of participation. These issues were extracted to develop the 'supports' for the 'rungs' of a conceptual model for e-learning-the e-learning ladder. 


\section{The e-learning ladder-a conceptual model}

In contrast to the five-stage model, the e-learning ladder (Moule, 2005) acknowledges a range of learning approaches, starting at the bottom 'rung' with an isolated approach to learning that might be termed as instructivist and moving through the 'rungs' ending with constructivist, or interactive learning approaches (see Figure 1). Through the inclusion of different learning approaches from isolated through to interactive learning, it acknowledges that not all e-learning is constructivist or course based and reflects the range of e-based learning materials available. Although not explicitly expressed, there is an expectation that the e-resources introduced might be used as part of a blended learning approach or incorporated within classroom deliveries. For example, learners using CD-ROMs or web-based materials to gain essential knowledge to support skill development are likely to attend a face-to-face skills practice session to develop the practical skills to compliment theoretical learning.

The structure of a ladder is not meant to imply that students must move up through each 'rung' to reach the top; rather, it is a presentation of a conceptual ladder of learning. It shows how learning might be positioned at instructivist to constructivist levels. Although presented hierarchically in a ladder structure, it is intended that the 'rungs' should be viewed as presenting flexible pedagogies, which inter-link. It is additionally suggested that the 'rungs' might be developed over time to allow the incorporation of
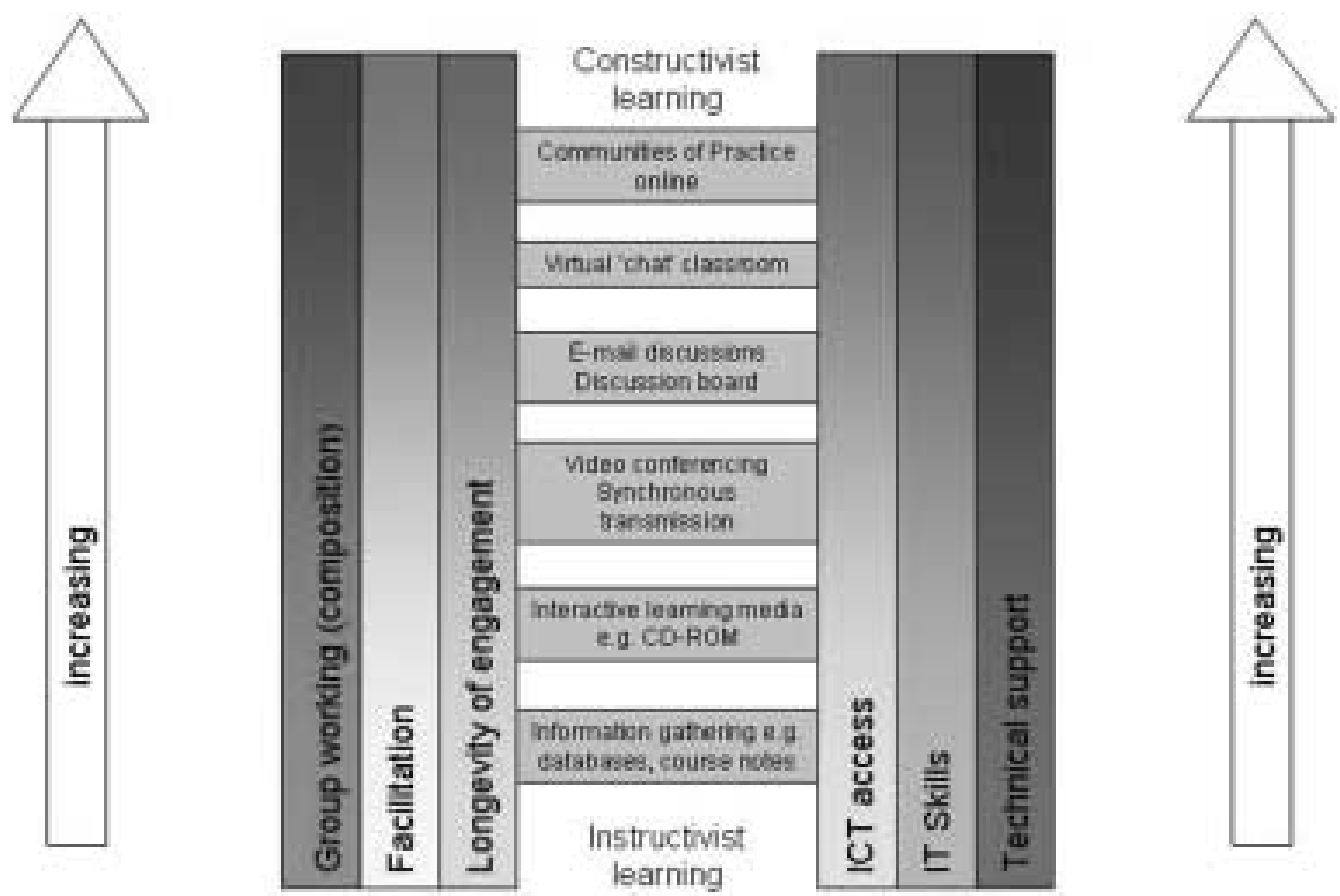

Figure 1. A conceptual model of online learning: the e-learning ladder 
new methods of e-delivery, such as the expanding use of mobile technologies, to support learning in higher education.

\section{The ladder 'rungs'}

The initial 'rung' includes information gathering that might encompass using bibliographic databases to search for material and accessing course notes. Rusby's (1979) classification of software would see this level as emancipatory, where the computer acts as an aid to learning but is not central to the learning process. It enables the student to access material that might support their learning.

The second 'rung' incorporates the use of interactive media for learning, such as CD-ROMs. The level of interaction is limited to the learner working with the educational media. This would be seen as the instructional paradigm (Rusby, 1979), where information is presented, broken into steps to aid learning. This reflects a behavourist approach to learning pioneered by Skinner, where specific steps in the process must be learned and followed (Nye, 1996). One example is a basic life-support CD-ROM developed to support competency development. It includes the steps in the skill, and tests assess the learner's knowledge of the topic (Moule \& Gilchrist, 2001). Materials at this level might also include those with simulations and animations to explore the real world, viewed as the revelatory paradigm (Rusby, 1979). A statistical program allowing learners to change the values of variables (Adams, 2004) provides one example. These packages engage learners in exploratory learning and 'mental model building', a constructivist technique that also features in the higher 'rungs' and as such is an example of the inter-linking of pedagogies between the 'rungs'. Materials can be further developed to meet Rusby's (1979) definition of the conjectural paradigm. These materials provide greater scope for learners to set their own learning parameters; for example, through conducting virtual experiments (Bell, 1999).

The higher 'rungs' encompass learning approaches that would be seen as constructivist. They encourage the learner to think creatively and problem-solve, update knowledge and skills, and develop analysis, critical thinking and evaluation (Adams, 2004). The final three 'rungs' of the ladder include aspects of interaction and engagement, although they suggest an incremental development of this, with the greatest scope for learning through interaction and discussion being placed within the higher rungs. These 'rungs' support a social constructivist approach to learning based on the theories of Vygotsky (1978), where learning is constructed through social interaction.

Video conferencing on the third 'rung' allows synchronous transmission of learning materials. The learner will engage by listening to delivery and may interact through questioning and verbal discussion. This may support debate, argument and reflection in knowledge creation, also seen as present within the next 'rung'. The fourth 'rung' presents discussion boards and email. These allow students to interact online through asynchronous communication as the fifth 'rung'. This approach gives scope for student-led debate and interaction that contributes to knowledge creation. The 
virtual classroom enhances communication opportunities, providing a vehicle for synchronous communication, used by the students for decision-making. This is viewed as enhancing opportunities for effective online communication, essential to knowledge development. At the top of the ladder is Communities of Practice (Wenger, 1998), where interaction among learners is vital to the development of mutual engagement, joint enterprise and shared repertoire. The development of identity is dependent on engagement in the community, with knowledge and learning being constructed through understanding gained within the community. Engagement in a community might require the student to employ all of the learning approaches identified in the lower 'rungs'. This can include drawing on databases to access information to support the community endeavour and engaging in the use of discussion boards, email and virtual classroom to communicate, problem-solve and support decision-making with community members.

\section{The ladder 'sides'}

The 'sides' of the ladder demonstrate the support needed for learners to access the 'rungs'. These results are drawn from the study data (Moule, 2005) and are presented here as verbatim quotes labelled DB1-DB7 (discussion board members), D1-D5 (online diaries) and as attributed to interviewees I1-I3. There is the potential for support to increase as the student climbs the ladder, depicted by the arrows at the 'sides'. Learners may require greater support in some areas as the technological complexity of the online environment increases, although this need not be uniform. For example, as part of the research study not all the learners experienced difficulties in the use of virtual classrooms and discussion boards, requiring the development of ICT skills. This said, often those with some computer familiarity are required to develop ICT skills in certain contexts. Andrusyszyn et al. (1999), in evaluating computer conferencing, found that despite nurses having access to home computers, the Internet and using email, they needed technical guidance in the use of computer conferencing technology.

Access. Access coupled with motivation forms the first stage of Salmon's (2003) model. At this stage Salmon refers to the need for e-moderators and participants to gain access to the online system. It is suggested that participants may need some technical support at this point to facilitate access. The e-learning ladder also includes access as a potential issue, but relates it to all e-based learning, suggesting that access issues might increase for some users as the technological complexity of the online environments intensify. Access is therefore not viewed merely as initial but as ongoing issue, as one student without computer access at home highlights.

I think I lost nearly two stone walking into Uni, that's the biggest advantage of online learning. (DB1)

Access to appropriate ICT hardware, software and network connections is required to support e-learning, and is often problematic to learners. 
Just to let you know that this weekend the Uni computer system is shutting down-so I have the weekend off. (DB3)

Radiographers have been unable to access BB [Blackboard] for a number of days. (D3)

An earlier study highlights access difficulties seen for higher education students, supporting these findings. McMahon et al. (1999), sampling 835 first-year students in Belfast, found students experienced access difficulties that proved to be a barrier to computer use.

A further concern is access for those with disabilities. Difficulties can exist for the visually impaired, colour blind, deaf and those unable to operate a mouse. Such disabilities can affect individual ability to engage with the computer and access visual imagery such as graphics and colour and audio presentation. ${ }^{2}$ All educational institutions need to comply with the Disability Discrimination Act 1995 (Her Majesties Stationery Office, 1995) and Special Educational Needs and Disability Act (Her Majesties Stationery Office, 2001).

Technical skills. The need for increased technological skill development among elearners was identified by Andrusyszyn et al. (1999) in an evaluation of computer conferencing that confirmed the need for technological guidance in the use of technology. Boyle and Wambach (2001), Curtis et al. (2002) and Hong et al. (2003) comment on a lack of confidence and fear as barriers to using technology for online learning, following research with postgraduate students studying in higher education. Indeed, students in this study noted,

I'm ... an adult nurse who is very scared about IP3 [online module]. (DB7)

For me personally, getting to grips with the IT side of it. My confidence was one or two ...'(I1)

Salmon (2003) reflects on the possible need to support participants with technical skills at different stages of the model, although referring to these as technical support. The ladder demonstrates that the technical skills of learners will need consideration across a range of e-learning materials and deliveries, with the possibility of the need for such skills to increase as the engagement in e-learning becomes more complex. This was seen in the research results as students familiar with computer use at the lower 'rungs' found use of components of the virtual learning environment difficult.

There were no problems with going online, although it took me ten minutes to work out how to use the virtual classroom. (D1)

The ladder separates technical skills from technical support, however, highlighting the need for ongoing support for computer-based learning, whether it employs instructivist or constructivist learning approaches.

Technical support. Not only do learners potentially need support with initial access to hardware, learning resources and networks, but also issues can arise with ongoing 
technological delivery. Cooper and McConnell (2000) identified that technical issues were one of the least favourite aspects of a web-based tool supporting physiotherapy student learning in Scotland. A number of students involved in this research experienced problems with password access to the virtual learning environment (Moule, 2005) and further examples of the need for ongoing technical support were highlighted.

Sometime during the day it was difficult to get into the Blackboard. A message kept saying that the request to get into the Blackboard was timed out. (D1)

After entering the v-classroom about twenty mins into the conversation I was thrown out of the classroom ... This also happened to other members. (D2)

It is suggested that the need for technological support may increase with the complexity of the learning environment being used, although some may have greater ICT skills than others, eliminating the need for technical support. This does not detract from the need for educational providers to ensure technical support is available and accessible. Atack (2003) provides an example of users failing to ask for technical help when needed, which stemmed from their lack of ICT knowledge.

Facilitation. Bender (2003) suggests that the role of the facilitator is important in supporting initial socialisation and ongoing maintenance of online groups. Salmon's (2003) model focuses on the role of the e-moderator, identifying the different emoderating skills required in each of the five stages. This component of the model seeks to enable e-moderators, offering practical guidance to those facilitating student engagement in online learning. The e-moderator role is further supported through a second publication (Salmon, 2002) that concentrates on e-activities.

A number of international studies conducted in higher education settings identify student dissatisfaction with online tutor support (Hara \& Kling, 2000; Monteith \& Smith, 2001; Hong et al., 2003). This discord seems to reflect the frustration felt by students, who identify a lack of online interaction with their facilitators. Monteith and Smith (2001) suggest this may be related to difficulties experienced by moderators of constructivist approaches to learning who are unsure when they should interject.

Facilitation is highlighted as a necessary support for all e-learners throughout the ladder, including those engaged in constructivist learning approaches. A number of students looked to the facilitator to address specific questions such as one enquiring about the style of presentation needed for the assessment.

I was wondering about the use of the first person ... (DB2)

It is felt that online facilitation will be increased when employing these learning approaches, but that there may still be a need for facilitation for those using interactive learning media or gathering web-based information. The facilitation need not always be conducted in the online context, but may relate to the preparation of participants for learning and any subsequent activities or learning that relate to the use of materials or development of skills that might occur in a face-to-face setting. In 
other words, the facilitation may occur as part of a blended approach to learning, where the application of e-based learning or information is facilitated.

Group working. The e-learning ladder includes group working and composition as one of the 'sides'. Group composition was seen as important to the functioning of the Communities of Practice as it was felt to impact on group working. The discussion group members had pre-established friends in the group. This group worked effectively, developing shared repertoire and forming relationships during the module.

I agree that we should follow the learning outcomes, then maybe adapt some of them to our group's needs. (DB4)

Other students also felt they had developed relationships within their groups, with one stating:

Two days before submission people were putting up supportive messages. (I2)

Previous knowledge of group members has been found to aid group functioning. As part of Australian research with 114 business students, Andrews and Schwarz (2002) found learning behaviours were linked to team performance, with those teams where members already knew each other performing more highly.

The initial phase of the research also saw time spent on social learning as individuals tried to socialise into the group, although for some online socialisation was problematic. For example, one student felt that relationship-building for her was best achieved in a face-to-face environment:

For group working for me, I would like to know the people I am working with. (I3)

Effective learning online requires the support of underpinning social processes, as team relationships have an impact on performance. Joiner (2004) also asserts that the assumed advantages of constructivist online learning are being challenged, with recent research showing there is no evidence of equal participation. Indeed one student commented on such issues.

There only seem to be myself and two others who are pulling our weight! (D5)

There is a need to create effective social collaboration and networking between members as computer-mediated learning will not automatically lead to effective collaboration. The five-stage model (Salmon, 2003) includes the interactivity bar, which assumes interaction between the e-moderator and group members. This is also implied through the engagement expected throughout the stages, including online socialisation and information exchange. Salmon (2003) also discusses the use of structured exercises and assessment that encourage student participation and group functioning. Group working is obviously a fundamental requirement for constructivist approaches to learning, and consideration of initial group composition or socialisation processes will aid its development. The ladder includes group composition and working as a facet for consideration across different learning approaches that might be employed. Although the need for effective group functioning is seen as increasing as more constructivist approaches are used, there is recognition that students may be 
using interactive learning materials or gathering information as part of a group, or indeed use these approaches to inform a Community of Practice.

Longevity of engagement. Longevity of engagement is a feature affecting the online learning environment, particularly if a constructivist learning approach is used. Indeed, those employing the five-stage model have commented on the difficulties of use in the short time-frame proposed (Lisewski \& Joyce, 2003; Chowcat, 2005). The period of engagement is of particular concern where there are expectations that a Community of Practice will emerge (Moule, 2005, 2006a). The role of shared histories in the development of a Community of Practice, it is suggested, will render unfeasible their development in short term courses (Fowler \& Mayes, 1999). A shortened period of engagement can affect the commitment of the participants, as seen in this research where one student preferred to maintain contact with existing peers rather than invest in a short lived community.

The majority of the information I am getting is obtained from fellow students not in my [online] group. (D5)

It will also adversely affect the development of shared repertoire, which will emerge over a long period of engagement. Given these concerns, longevity of engagement is a component of the ladder, seen as increasing in emphasis at the top of the ladder, when participants are engaging in more constructivist learning approaches. The 'side' representing engagement extends the full length of the ladder, acknowledging the need for participant engagement at every level of learning.

\section{Conclusions}

This paper has offered a critical review of the five-stage model, comparing it with the e-learning ladder and highlighting the different interpretations of e-learning presented in each. Discussions have also identified areas of similarity seen, where both the five-stage model and the e-learning ladder include the factors necessary to enable engagement in e-learning environments such as access and technical support. In presenting such dialogue the paper makes a contribution to the current agendas that seek to understand learner participation in, and experiences of, e-learning.

The discussion challenges the view that e-learning in higher education must reflect a constructivist approach to learning, reinforcing the opportunities for e-learning to support instructivist approaches, blended learning and classroom supported delivery. The e-learning ladder is offered as a conceptual model that provides one interpretation of e-learning, which in the future might be expanded to incorporate the potential of mobile technology deliveries within higher education.

\section{Notes}

1. See www.jisc.ac.uk/elearning

2. See www.techdis.ac.uk 


\section{References}

Adams, A. (2004) Pedagogical underpinnings of computer-based learning, fournal of Advanced Nursing, 46(1), 5-12.

Andrews, T. \& Schwarz, G. (2002) Preparing students for the virtual organisation: an evaluation of learning with virtual learning technologies, Educational Technology and Society, 5(3), 54-65. Available online at: http://ifets.ieee.org/perodical/vol_5_2002/andrews.html (accessed 11 March 2003).

Andrusyszyn, M., Iwasiw, C. \& Goldenberg, D. (1999) Computer conferencing in graduate nursing education: perceptions of students and faculty, The fournal of Continuing Education in Nursing, 30(6), 272-278.

Armitage, S. \& O'Leary, R. (2003) A guide for learning technologists (York, Learning and Teaching Support Network Generic Centre).

Atack, L. (2003) Becoming a web-based learner: registered nurses' experiences, fournal of Advanced Nursing, 44(3), 289-297.

Barker, P. (2002) On being an online tutor, Innovations in Education and Teaching International, 39(1), 7-13.

Beetham, H. (2005) e-Learning research: emerging issues?, ALT-f, 13(1), 81-89.

Bell, J. (1999) The biology labs on-line project: producing educational simulations that promote active learning, Interactive Multimedia Electronic fournal of Computer Enhanced Learning. Available online at: http://imej.wfu.edu/articles/1999/2/01/index.asp (accessed 5 June 2003).

Bender, T. (2003) Discussion-based online teaching to enhance student learning. Theory, practice and assessment (Sterling, VA, Stylus Publishing).

Bennett, S. \& Marsh, D. (2002) Are we expecting online tutors to run before they can walk?, Innovations in Education and Teaching International, 39(1), 14-20.

Boyle, D. \& Wambach, K. (2001) Interaction in graduate nursing web-based instruction, fournal of Professional Nursing, 17(3), 128-134.

Chalk, P. (2001) Learning software engineering in a Community of Practice-a case study, paper presented at the CAL 2001 Conference, Warwick University. Available online at: http:// www.ics.ltsn.ac.uk/pub/conf2001/papers/Chalk.html (accessed 24 May 2004).

Chowcat, I. (2005) Models of e-learning: the importance of context, paper presented at $A L T-C$ 2005 12th International Conference, Manchester University, UK.

Cooper, V. \& McConnell, M. (2000) Development of a web-based learning tool for undergraduate health professions studying applied anatomy, $A L T-\mathcal{F}, 8(1), 62-69$.

Curtis, E., Hicks, P. \& Redmond, R. (2002) Nursing student's experience and attitudes to computers: a survey of a cohort of students on a Bachelor in Nursing Studies Course, Information Technology in Nursing, 14(2), 7-17.

Department for Education and Skills (2005) The e-Strategy-harnessing technology: transforming learning and children's services (London, DfES). Available online at: http://www.dfes.gov.uk/ publications/e-strategy/exec.shtml (accessed 7 October 2005).

Ellaway, R., Dewhurst, D. \& McLeod, H. (2004) Evaluating a virtual learning environment in the context of its community of practice, ALT-F, 12(2), 125-145.

Fowler, C. \& Mayes, J. (1999) Learning relationships from theory to design, $A L T-\mathcal{F}, 7(3), 6-16$.

Good, M. (2001) On the way to online pedagogy, in: J. Stephenson (Ed.) Teaching and learning online: pedagogies for new technologies (London, Kogan Page), 166-174.

Hara, N. \& Kling, R. (2000) Students' distress with a web-based distance education course: an ethnographic study of participants' experiences (Bloomington, IN, Center for Social Informatics, SLIS, Indiana University). Available online at: http://www.slis.indiana.edu/CSI/WP/wp0001B.html. (accessed 14 October 2005). Also in Information, Communication and Society, 3(4), 557-579.

Her Majesties Stationery Office (1995) Disability Discrimination Act 1995 (DDA) Available online at: http://www.hmso.gov.uk/acts/acts1995/1995050.htm (accessed 7 January 2005). 
Her Majesties Stationery Office (2001) Special Educational Needs and Disability Act 2001 (SENDA). Available online at: http://www.hmso.gov.uk/acts/acts2001/20010010.htm (accessed 7 January 2005).

Hildreth, P. (2004) Going virtual: distributed Communities of Practice (Hershey, PA, Idea Group Publishing).

Hong, K.-S., Lai, K.-W. \& Holton, D. (2003) Students' satisfaction and perceived learning within a web-based course, Educational Technology and Society, 6(1). Available online at: http:// ifest.ieee.org/periodical/vol_1_2003/hong.html (accessed 11 March 2003).

Hughes, M., Ventura, S. \& Dando, M. (2004) On-line interprofessional learning: introducing constructivism through enquiry-based learning and peer review, fournal of Interprofessional Care, 18(3), 263-268.

Joiner, R. (2004) Supporting collaboration in virtual learning environments, CyberPsychology and Behaviour, 7(2), 197-200.

Jones, N. \& Peachey, P. (2005) The development of socialization in an on-line learning environment, Fournal of Interactive Online Learning, 3(3), 1-20. Available online at: http://www.ncolr.org/jiol/ issues/showissue.cfm?volID=3\&IssueID=12 (accessed 11 November 2005).

Lisewski, B. \& Joyce, P. (2003) Examining the five-stage e-moderating model: designed and emergent practice in the learning technology profession, $A L T-\mathcal{F}, 11(1), 55-66$.

McMahon, J., Gardner, J., Gray, C. \& Mulhern, G. (1999) Barriers to student computer usage: staff and student perceptions, fournal of Computer Assisted Learning, 13(4), 302-311.

Monteith, M. \& Smith, J. (2001) Learning in a virtual campus: the pedagogical implications of students' experiences, Innovations in Education and Teaching International, 38(2), 119-127.

Moule, P. (2002) Evaluation of a basic life support CD-ROM: its effectiveness and user experiences, Educational Technology and Society, Special Edition Evaluation of Learning Technologies in Higher Education, 5(3), 163-174. Available online at: http://ifets.ieee.org/ periodical/vol_3_2002/v_3_2002.html (accessed 7 October 2005)

Moule, P. (2005) E-learning for healthcare students: developing the communities of practice framework. Ed.D. thesis, University of the West of England, Bristol.

Moule, P. (2006a) E-learning for healthcare students: developing the Communities of Practice framework, Fournal of Advanced Nursing, 53(3), 370-380.

Moule, P. (2006b) E-communities, in: S. Glen \& P. Moule (Eds) E-learning in nursing (Basingstoke, Palgrave).

Moule, P. \& Gilchrist, M. (2001) An evaluation of a basic life support CD-ROM, Health Informatics Fournal, 7(1), 28-35.

Nye, R. (1996) Three psychologies. Perspectives from Freud, Skinner and Rogers (New York, Brooks/ Cole Publishing).

Peters, M. (2000) Does constructivist epistemology have a place in nurse education?, fournal of Nursing Education, 39(4), 166-172.

Rogers, J. (2000) Communities of practice: a framework for fostering coherence in virtual learning communities, Educational Technology and Society, 3(3), 1-12. Available online at: http:// ifets.ieee.org/periodical/vol_3_2000/eo1.html (accessed 11 March 2003).

Rusby, N. J. (1979) An introduction to educational computing (London, Croom Helm).

Salmon, G. (2000) E-moderating: the key to teaching and learning online (London, Kogan Page).

Salmon, G. (2002) E-tivities (London, Kogan Page).

Salmon, G. (2003) E-moderating (2nd edn) (London, Routledge Falmer).

Seale, J. (2004) The development of accessibility practices in e-learning: an exploration of communities of practice, $A L T-7,12(1), 51-63$.

Somekh, B. \& Pearson, M. (2000) Inter-cultural learning arising from pan-European collaboration using electronic communications: sub-text or substance?, paper presented at the British Educational Research Association Annual Conference, Cardiff, UK, September.

Thorpe, M. (2002) Rethinking learner support: the challenge of collaborative online learning, Open Learning, 17(2), 105-115. 
Vygotsky, L. (1978) Mind in society (Cambridge, MA, Harvard University Press).

Wenger, E. (1998) Communities of practice (Cambridge, Cambridge University Press).

Wong, S. L., Jahil, H. A., Ayub, A. F. M. \& Hong, T. S. (2003) Teaching a discrete information technology course in a constructivist learning environment: is it effective for Malaysian preservice teachers?, The Internet and Higher Education, 6(2), 193-204.

Yin, R. (1994) Case study research. Design and methods (2nd edn) (London, Sage). 